\title{
Significance of Wharton's jelly area in prediction of aberrant foetal growth
}

\author{
Sapna Amin, Shripad Hebbar*, Deepika Pothakamuri, Prashant Adiga
}

Department of Obstetrics and Gynecology, KMC Manipal, Manipal Academy of Higher Education, Manipal, Karnataka, India

Received: 11 May 2018

Accepted: 02 June 2018

*Correspondence:

Dr. Shripad Hebbar,

E-mail: drshripadhebbar@yahoo.co.in

Copyright: (c) the author(s), publisher and licensee Medip Academy. This is an open-access article distributed under the terms of the Creative Commons Attribution Non-Commercial License, which permits unrestricted non-commercial use, distribution, and reproduction in any medium, provided the original work is properly cited.

\begin{abstract}
Background: Size of the baby at the time birth determines its outcome. Low birth weight babies have their own set of problems such as respiratory distress syndrome, hypoxic ischemic encephalopathy, metabolic derangements and high rates of admission to intensive care units. On the other hand too large babies may cause difficulty in vaginal births, higher incidence of birth trauma including the maternal genital injuries. Both conditions are associated with higher rates of operative delivery and hence it is important to investigate parameters which could identify these foetal growth abnormalities in the antenatal period only. The objective of the present investigation was to study the relationship between foetal umbilical cord Wharton's Jelly Area and neonatal birth weight within two weeks of delivery

Methods: A prospective observational study was conducted at Department of Obstetrics and Gynaecology, Kasturba Medical College, Manipal, Karnataka, India over a period of two years. Two hundred and fifty women from 34 weeks gestational age who have delivered within two weeks of estimation of Wharton's Jelly Area by ultrasound were analysed. Wharton's Jelly Area was measured in pregnant woman after 34 weeks of gestation at the time of third trimester scan. Scans were repeated every two weeks till the woman delivered. Measurements were done in a free loop of the umbilical cord. Regression analysis was used to correlate Wharton's jelly quantity with the birth weight obtained after birth of the neonate.

Results: There was a good correlation between Wharton's Jelly Area and neonatal birth weight. The mean birth weight was $2247.2 \mathrm{gms}$ in < than $10^{\text {th }}$ centile group, $2945.1 \mathrm{gms}$ in $10^{\text {th }}$ to $90^{\text {th }}$ centile and 3552.1 gms in more than 90th centile group, demonstrating a consistent rise in mean birth weight with higher centile groups. Polynomial regression function showed good fit between Wharton's jelly and birth weight $\left(\mathrm{R}^{2}=0.8842, \mathrm{p}<0.001\right)$. When Wharton's jelly area was less than 10th centile, $72 \%$ of neonates had small for gestational age (SGA).

Conclusions: There is a positive association between Wharton's Jelly Area and neonatal birth weight. Birth weight of neonate showed steady increase with increasing Wharton's Jelly Area.
\end{abstract}

Keywords: Macrosomia (LGA), Neonatal birth weight, Small for gestational age (SGA), Wharton's Jelly Area

\section{INTRODUCTION}

Now it is well known that neonatal outcome depends upon size at birth. Smaller babies face with problems of respiratory distress syndrome, necrotising enterocolitis, hypothermia, metabolic disturbances. On the contrary, large babies invariably have the background of maternal diabetes, risk sudden death inutero, vaginal delivery in them is associated with both maternal and foetal injuries due to birth trauma and after birth also may suffer from complications due to hypoglycaemia and hypobilirubinaemia. Hence it is very important to diagnose these abnormalities of foetal size well in advance so that necessary interventions are taken to 
reduce morbidity and mortality associated with birth of these neonates.

These growth abnormalities are basically diagnosed by plotting ultrasonically obtained foetal weight against the gestational age on a predefined growth curve which shows birth weight centiles at corresponding gestational age. In fact, all the modern obstetric ultrasound equipments have preinstalled software which automatically calculates and plots these values and prints the report. The gestational age is plotted on " $\mathrm{X}$ " axis and estimated foetal weight (obtained by Hadlock formula. ${ }^{1}$ using Biparietal Diameter [BPD], Head Circumference [HC, Abdominal Circumference (AC) and Femur Length [FL]) is plotted on "Y" axis and the foetal growth is assumed to be normal if it falls between $10^{\text {th }}$ and $90^{\text {th }}$ centile. Small for gestational age (SGA) refers to foetuses with birth weight less than 10th centile for gestational age and on the other hand large for gestational age refers to foetuses with birth weight more than $90^{\text {th }}$ centile. $^{2}$ Unfortunately, only $50 \%$ growth restricted foetuses are timely identified in antenatal period. ${ }^{3}$

Paediatric observations indicate that amount of Wharton's jelly in the umbilical cord positively correlates with the birth weight. ${ }^{4}$ Pathological examination has revealed that umbilical cord abnormalities such as variation in number of vessels, Wharton's jelly content, cord thrombosis, varices etc., may exist in foetal growth abnormalities. ${ }^{5}$ Prenatal assessment of umbilical morphology has revealed interesting association between predicted birth weight and umbilical cord thickness, cross sectional area, circumference and Wharton's jelly content. $^{5,6}$ Intrauterine growth delay can occur in abnormalities of the umbilical cord, like single umbilical artery and velamentous cord insertion. ${ }^{7} \mathrm{~A}$ thin and lean umbilical cord is reported to be associated with SGA neonates. ${ }^{8}$ On the contrary large umbilical cord area is associated with macrosomic babies. ${ }^{9}$ Both lean and large cords are mainly determined by amount of Wharton's jelly surrounding the two umbilical arteries and one umbilical vein and hence prenatal estimation of Wharton's jelly content is a useful aid for diagnosing extreme ranges of foetal weight. With modern highresolution ultrasound techniques, it has now become possible to study umbilical cord morphometry in greater details.

The purpose of this study was to determine whether there is a correlation between sonographic measurements of Wharton's Jelly Area in the umbilical cord and actual birth weight. This association may serve Wharton's jelly as additional single parameter in identifying growth abnormalities.

\section{METHODS}

Authors conducted a prospective observational study in the Department of Obstetrics and Gynaecology, Kasturba Hospital, Manipal over a period of two years. Authors' centre serves as a main teaching hospital for Kasturba Medical College, Manipal and currently is recognized as a tertiary referral hospital for Udupi and its four surrounding districts. Authors recruited 250 pregnant women after 34 weeks of gestation, who were followed up with two weekly scans till they delivered. All the participants gave consent for enrolment to the study. The study protocol was approved by institutional regulatory authorities.

\section{Inclusion criteria}

- $\quad$ singleton pregnancies

- presence of three vessel umbilical cord and intact membranes.

\section{Exclusion criteria}

- pregnancies with multiple gestation

- intrauterine foetal demise

- congenitally malformed fetuses

- women who had Prelabour Rupture of membranes (PROM).

Pregnancies were accurately dated depending upon reliable last menstrual period (LMP) and first trimester Crown Rump Length (CRL) measurements. We used Philips HD11XE ultrasound equipment which had capability of real time 2D mode and integrated colour Doppler for accurate identification of free loop of umbilical cord. First authors obtained accurate transverse section of umbilical cord preferably in a good amniotic pocket so that cord margin could be accurately delineated. There after the region of interest (ROI) was focussed and further zoomed so that calliper tracing could be done as precisely as possible. The ellipse function of the ultrasound machine was used in all cases and the bestfitting ellipse was put over the umbilical cord and its vessels. The area of Wharton's jelly was calculated by subtracting the total vessels area (arteries and vein) from the umbilical cord area (Figure 1).

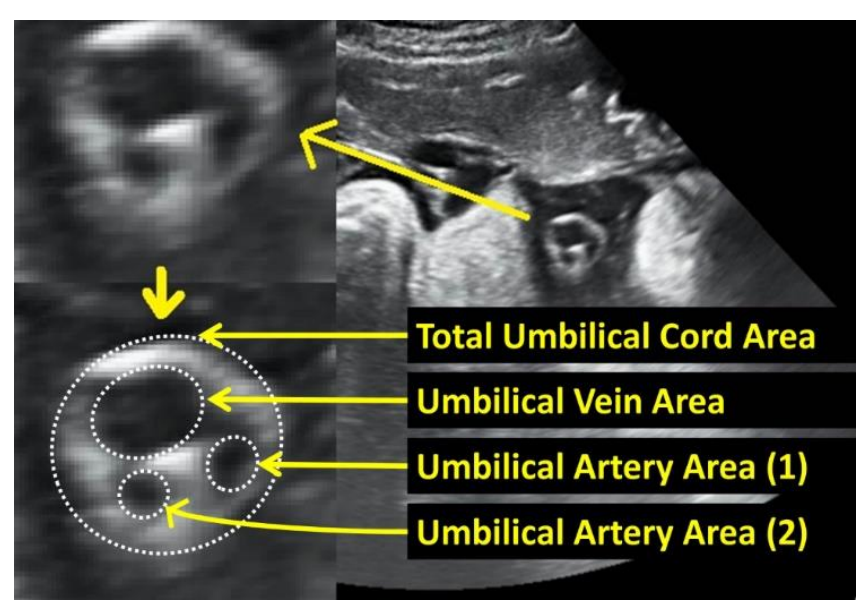

Figure 1: Method of obtaining Wharton's Jelly Area. 
Wharton's Jelly Area = Total umbilical cord area $-($ Area of first umbilical artery + Area of second umbilical artery + Area of umbilical vein).

Wharton's jelly area percentile calculation was done and divided into three groups; less than $10^{\text {th }}$ centile, $10^{\text {th }}$ to $90^{\text {th }}$ centile and more than $90^{\text {th }}$ centile.

Newborn was weighed using electronic weighing machine in grams. For comparison purpose, they were divided into again three groups similarly above, i.e., less than 10th centile (SGA- Small for Gestational Age group), 10th to 90th centile (Appropriate for Gestational Age group - AGA) and more than 90th centile (Large for Gestational Age - LGA group). Group wise comparison was done to establish correlation between Wharton' jelly area and neonatal birth weight.

\section{Sample size estimation}

Ghezzi et al. have reported that Wharton's jelly area at 34 weeks of gestation is $140.21 \mathrm{~mm}^{2}$ with standard deviation of $37.28\left(\mathrm{~mm}^{2}\right) .{ }^{10}$ Authors hypothesised that $20 \mathrm{~mm}^{2}$ deviations from above mentioned mean value would identified abnormal group. The following formula was used for sample size estimation.

$$
n=\frac{2\left(z_{1}-\alpha / 2+z_{1}-\beta\right)^{2}}{\left(\frac{\mu_{0}-\mu_{1}}{\sigma}\right)^{2}}
$$

Where $Z 1-\alpha / 2$ is equal to 1.96 (for $\alpha=0.05$, i.e. type I error), $Z 1-\beta / 2$ is equal to 0.84 (for $\beta=0.20$, i.e. type II error), $\mu 0-\mu 1$ is equal to the difference of means $(20 \mathrm{~mm} 2$ as in quoted study), $\sigma$ is the standard deviation (37.28 $\mathrm{mm} 2$ ). This equation gave expected power of 0.80 . Accordingly, the sample size required was 54 and present sample size of 250 was far more than adequate.

\section{Statistical analysis}

Statistical Package for Social Sciences 16.0 (SPSS Inc. Chicago, IL, USA) was used for Statistical analysis. The comparison of outcome among the study group was done by Chi-square test and Pearson correlation wherever applicable. One-way ANOVA was used to compare the means birth weight in three different groups of Wharton's jelly area. $P$ value less than 0.05 was considered statistically significant. Microsoft Excel 2010 was used to plot interaction between Wharton's jelly area and neonatal birth weight.

\section{RESULTS}

Among 250 pregnant women recruited for the study, 150 $(60 \%)$ were primigravida and $100 \quad(40 \%)$ were multigravida. Age of majority of the women was within
20 to 30 years range $(86.8 \%)$ and only $13.2 \%$ women were beyond 30 years of age. The mean Wharton's jelly area was 149.73 with a standard deviation of $28.75 \mathrm{~mm}^{2}$. The Wharton's jelly area was in the range of $89-207$ $\mathrm{mm}^{2}$. The $10^{\text {th }}$ and the $90^{\text {th }}$ percentile values were 112 $\mathrm{mm}^{2}$ and $198 \mathrm{~mm}^{2}$ respectively. Accordingly, Authors divided 250 patients in 3 groups, A. Wharton's jelly area $<$ than 10th centile (25 in the group (10\%)), B. Wharton's jelly area within $10^{\text {th }}$ to $90^{\text {th }}$ centile (197 in the group $(78.8 \%)$ ) and C. Wharton's jelly area $>$ than $90^{\text {th }}$ centile (28 in the group (11.2\%)).

The mean birth weight of the neonates at the time of birth was 2943 grams with a standard deviation of 413 grams. The birth weight was in the range of 1740 - 4180 grams. The $10^{\text {th }}$ and the $90^{\text {th }}$ percentile values were 2400 and 3499 grams respectively. Hence cases with birth weight $<2400$ grams were categorized as small for gestational age infants (SGA), birth weight between 2400 grams and 3499 grams were grouped as appropriate for gestational age (AGA) and those with birth weight >3499 grams were categorised as large for gestational age (LGA) infants. Table 1 shows 3 × 3 crosstab tabulation between Wharton jelly area ranges and birth weight groups.

It can be very well seen from Table 1 that when Wharton's jelly area was less than $10^{\text {th }}$ centile, $72 \%$ of neonates had small for gestational age (SGA), with Wharton's jelly are of $10^{\text {th }}$ to $90^{\text {th }}$ centile, $91.4 \%$ of neonates were appropriate for gestational age (AGA) and but when Wharton jelly are was beyond $90^{\text {th }}$ centile, only $57.1 \%$ of babies had large for gestational age (LGA), moreover these findings were statistically significant.

Table 1: Distribution of patients according to Wharton's jelly area and neonatal birth weight.

\begin{tabular}{|llll|}
\hline \multicolumn{4}{|c|}{ Birth weight categories } \\
\hline & SGA & AGA & LGA \\
\hline $\begin{array}{l}\text { Wharton's Jelly } \\
\text { area groups }\end{array}$ & $\mathrm{n}(\%)$ & $\mathrm{n}(\%)$ & $\mathrm{n}(\%)$ \\
\hline$<10^{\text {th }}$ Centile & $18(72)$ & $7(28)$ & $0(0)$ \\
\hline $10-90^{\text {th }}$ Centile & $10(5.1)$ & $180(91.4)$ & $7(3.6)$ \\
\hline$>90^{\text {th }}$ Centile & $0(0)$ & $12(42.9)$ & $16(57.1)$ \\
\hline \begin{tabular}{l}
$P$ value $<0.001$ \\
\hline
\end{tabular}
\end{tabular}

Table 2 shows analysis of means by one-way ANOVA in three groups of birth weight categories. It can be very well seen that the mean of Wharton's jelly area consistently increased as birth weight category changed from smaller birth weight size to large babies, which was statistically significant.

Authors also analysed changes in the birth weight in three different categories of Wharton's jelly area. Table 3 shows comparison of mean birth weight in three groups of Wharton's jelly area. Again, it can be very well seen that the mean birth weight consistently increased as Wharton's jelly area increased from lower percentile 
group to higher percentile group which reached high statistical significance.

Table 2: Descriptive analysis of Wharton's jelly area $\left(\mathrm{mm}^{2}\right)$ in three birth weight groups.

\begin{tabular}{|c|c|c|c|c|}
\hline $\begin{array}{l}\text { Birth } \\
\text { weight } \\
\text { categories }\end{array}$ & $\mathbf{N}$ & Mean & $\begin{array}{l}\text { Std. } \\
\text { deviation }\end{array}$ & Statistics \\
\hline SGA & 28 & 107.22 & 12.22 & \multirow{3}{*}{$\begin{array}{l}\mathrm{F}=126.28, \\
\mathrm{p}<0.001 \\
\text { (One way } \\
\text { ANOVA) }\end{array}$} \\
\hline AGA & 199 & 150.14 & 22.145 & \\
\hline LGA & 23 & 197.92 & 5.367 & \\
\hline
\end{tabular}

Table 3: Descriptive analysis of neonatal birth weight according to 3 group of Wharton's jelly area $\left(\mathrm{mm}^{2}\right)$.

\begin{tabular}{|lllll|}
\hline $\begin{array}{l}\text { Wharton's } \\
\text { jelly area }\end{array}$ & $\mathrm{N}$ & Mean & $\begin{array}{l}\text { Std. } \\
\text { deviation }\end{array}$ & Statistics \\
$\begin{array}{l}<10^{\text {th }} \\
\text { Centile }\end{array}$ & 25 & 2247.2 & 262.9 & $\begin{array}{l}\mathrm{F}=138.27, \\
\mathrm{p}<0.001 \\
\text { (One way } \\
\text { ANOVA) }\end{array}$ \\
$\begin{array}{l}10^{\text {th }} \text { to } 90^{\text {th }} \\
\text { Centile }\end{array}$ & 197 & 2945.1 & 294.1 & \\
\hline $\begin{array}{l}>90^{\text {th }} \\
\text { Centile }\end{array}$ & 28 & 3552.1 & 234.3 & \\
\hline
\end{tabular}

A regression analysis was carried out to study the interaction between Wharton's jelly area and neonatal birth weight. Figure 2 shows scatter diagram of Wharton's jelly area plotted on X axis and neonatal birth weight drawn on $\mathrm{Y}$ axis.

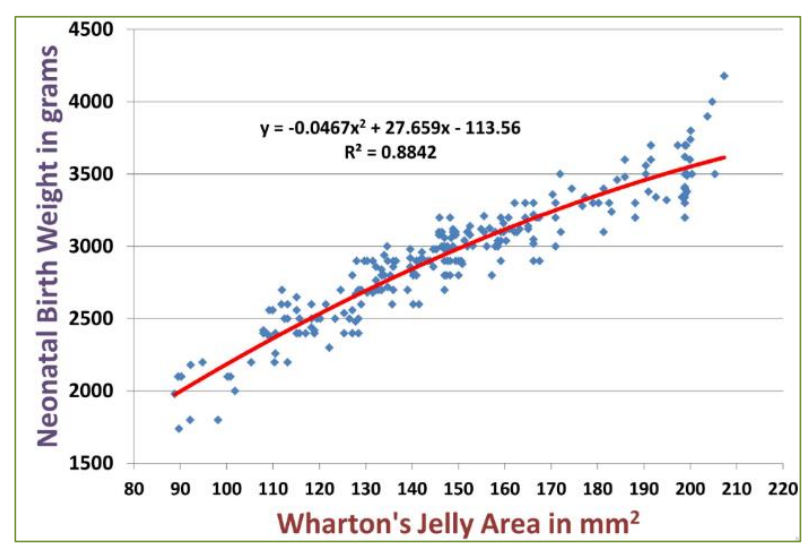

Figure 2. Scatter plot showing interactions between Wharton's jelly area and neonatal birth weight.

Microsoft Excel trend line function was used to which of the regression analysis (linear, polynomial, logarithmic or power function) relates the association between these two variables and it was found that polynomial function of second degree fits the relation well $(\mathrm{BW}=-0.0467 *[\mathrm{WJ}]$ $2+27.659 *[\mathrm{WJ}]-113.56, \mathrm{R}^{2}=0.8842, \mathrm{p}<0.001$, where in $\mathrm{BW}=$ Birth Weight and $\mathrm{WJ}=$ Wharton's jelly area in $\left.\mathrm{mm}^{2}\right)$.
Thus, all the statistical tests indicated that Wharton's jelly area is an important predictor of neonatal birth weight and is useful in all ranges of foetal weight.

\section{DISCUSSION}

The umbilical cord is the major link that provides communication between the placenta and the foetus. It contains porous Wharton's jelly which acts like a protective cushion for its contents, i.e. two umbilical arteries and one umbilical vein, preventing them from getting compressed and there by maintaining blood flow to the foetus. ${ }^{11}$ Embryologically it develops from extraembryonic mesoderm. It is named after English anatomist Thomas Wharton (1614-1673) who first described it in 1656 in his publication Adenographia, or "The Description of the Glands of the Entire Body". The ground substances that make Wharton's jelly include glycosaminoglycans, proteoglycans, and predominantly hyaluronic acid. The elastic nature of Wharton's jelly are due to combined presence of myofibroblasts and type I, II, and V collagen giving it contractive property. ${ }^{4}$ Umbilical cord elasticity confers resistance to external pressure, and acts as a physical buffer in the regulation of foetoplacental blood circulation and umbilical vessels. ${ }^{12}$ Wharton's jelly serves many functions, as a mucous tissue, it protects and insulates umbilical blood vessels. It has a cushioning effect on the umbilical cord vessels, so that the blood flow from placenta to foetus and vice versa is maintained within normal limits and helps in growth of the baby. When present in adequate quantity, it prevents cord compression. It is temperature sensitive and immediately after birth, it shrinks significantly thereby providing physiological clamping of cord vessels within 5 minutes, thereby preventing significant neonatal blood loss.

All great vessels have protective covering tunica adventitia which umbilical vessels anatomically lack and Wharton's jelly replaces function of the adventitia layer and prevents vascular accidents in the umbilical cord. Good amount of Wharton's jelly thereby appears to be vital to umbilical cord function and in some cases, the reduction in foetal growth could be directly associated with Wharton's jelly decrement, resulting in hypoplastic umbilical cord. If Wharton's jelly is insufficient in quantity the vessels remain unprotected, they become more prone to compression there by compromising the blood supply to the foetus, which in turn results in oligoamnios which itself leads to further episodes of cord compression and finally a vicious cycle sets in.,13

Reduction in Wharton jelly has been found in intrauterine growth restriction (IUGR) infants and small for gestational age (SGA) foetuse. ${ }^{14}$ Filiz et al. investigated the relationship between the amount of Wharton's jelly and its protective role in umbilical cord vessels, and hence, on foetal growth. ${ }^{4}$ Their study enrolled 299 women and concluded that the "quality" and characteristics of Wharton's jelly were both important in 
its protective role. Filiz et al. studied the possible protective effects of Wharton's jelly in umbilical cord and foetal growth by investigating the relationship between the amount of Wharton's jelly and foetal birth weight. ${ }^{4}$ The study included 299 women who delivered after an uneventful pregnancy. After separation of the placenta, a $5 \mathrm{~cm}$ long section of umbilical cord was removed by scalpel. The weight of the cord section; the weight, volume, and density of its Wharton's jelly; and the weight of the newborn and placenta were measured. A significant positive correlation was found between Wharton's jelly quantity, birth weight $(p=0.002)$, and placental weight $(\mathrm{p}=0.003)$, whereas a significant negative correlation was observed for Wharton's jelly density, foetal growth $(\mathrm{p}=0.035)$, and placental growth $(\mathrm{p}=0.002)$. They opined that abnormal situations, such as a decrease in the hyaluronic acid content of Wharton's jelly and Wharton's jelly fibrosis, may affect the mechanical characteristics of the cord, which leads to impaired foetal circulation, anoxia, and foetal death.

Gill et al studied postnatally 398 consecutively umbilical cords after emptying blood from them. ${ }^{15} \mathrm{~A}$ frozen segment was prepared from each of the sample. Three cross-sections were obtained from each cord, and dye imprints were made. Their surface area was measured by placing a transparency with a grid of squares over the imprint and counting the number of squares it occupied. An average of these three cross-sectional areas was taken to estimate the quantity of Wharton's jelly at any point along the umbilical cord. They found that large babies had greater quantity of Wharton's jelly wrapped around the umbilical cord vessels, compared normally weighed infants.

\section{CONCLUSION}

There is a positive correlation between Wharton's jelly area and birth weight meaning as area of Wharton's jelly increases birth weight also increases and vice versa as Wharton's jelly decreases birth weight also decreases. Too low quantity is associated with small for gestational age babies and too large quantity means foetal macrosomia. Estimation of Wharton's jelly may serve as a useful standalone parameter in assessing ranges of neonatal birth weight.

Funding: No funding sources

Conflict of interest: None declared

Ethical approval: The study was approved by the Institutional Ethics Committee

\section{REFERENCES}

1. Hadlock FP, Harrist RB, Sharman RS, Deter RL, Park SK. Estimation of fetal weight with the use of head, body, and femur measurements-a prospective study. Am J Obstet Gynaecol. 1985;151:333-7.
2. WHO. Physical status: the use and interpretation of anthropometry. Report of a WHO Expert Committee. World Health Organ Tech Rep Ser. 1995;854:1-452.

3. American College of Obstetricians and Gynecologists (ACOG) Practice bulletin no. 134: fetal growth restriction. Obstet Gynecol. 2013;121(5):1122-33.

4. Filiz AA, Rahime B, Keskin HL, Esra AK. Positive correlation between the quantity of Wharton's jelly in the umbilical cord and birth weight. Taiwan J Obstet Gynecol. 2011;50(1):33-6.

5. Di naro E, Ghezzi F, Raio L, Franchi M, D'addario V. Umbilical cord morphology and pregnancy outcome. Eur J Obstet Gynecol Reprod Biol. 2001;96(2):150-7.

6. Barbieri C, Cecatti JG, Surita FG, Marussi EF, Costa JV. Sonographic measurement of the umbilical cord area and the diameters of its vessels during pregnancy. J Obstet Gynaecol. 2012;32(3):230-6.

7. Redline RW. Clinical and pathological umbilical cord abnormalities in fetal thrombotic vasculopathy. Hum Pathol. 2004;35(12):1494-8.

8. Raio L, Ghezzi F, Di Naro E, Franchi M, Maymon E, Mueller MD, Brühwiler H. Prenatal diagnosis of a lean umbilical cord: a simple marker for the fetus at risk of being small for gestational age at birth. Ultrasound Obstetr Gynecol. 1999;13(3):176-80.

9. Cromi A, Ghezzi F, Di naro E, Siesto G, Bergamini $\mathrm{V}$, Raio L. Large cross-sectional area of the umbilical cord as a predictor of fetal macrosomia. Ultrasound Obstet Gynecol. 2007;30(6):861-6.

10. Ghezzi F, Raio L, Di naro E, Franchi M, Balestreri D, D'addario V. Nomogram of Wharton's jelly as depicted in the sonographic cross section of the umbilical cord. Ultrasound Obstet Gynecol. $2001 ; 18(2): 121-5$.

11. Ferguson VL, Dodson RB. Bioengineering aspects of the umbilical cord. Eur J Obstet Gynecol Reprod Biol. 2009;144 Suppl 1:S108-13.

12. 12. Takechi K, Kuwabane Y, Mizuna M. Ultrastructure and immunohistochemical studies of Wharton's jelly umbilical cord cells. Placenta. 1993; 14:235-45.

13. Labarrere C, Sebastiani M, Siminovich M, Torassa E, Althabe O. Absence of Wharton's jelly around the umbilical arteries: an unusual cause of perinatal mortality. Placenta. 1985;6:555-9.

14. Scott JM, Wilkinson R. Further studies on the umbilical cord and its water content. J Clin Pathol 1978;31:944-8.

15. Gill P, Jarjoura D. Wharton's jelly in the umbilical cord. A study of its quantitative variations and clinical correlates. J Reprod Med 1993; 38: 611-4.

Cite this article as: Amin S, Hebbar S, Pothakamuri D, Adiga P. Significance of Wharton's jelly area in prediction of aberrant foetal growth. Int J Reprod Contracept Obstet Gynecol 2018;7:2820-4. 